\title{
Building Customer Value And Profitability With Business Ethics
}

Robert C. McMurrian, (Email: rmcmurrian@uy.edu), University of Tampa Erika Matulich, (Email: ematulich@ut.edu), University of Tampa

\author{
ABSTRACT \\ Firms assume ethical business practices only add costs to the firm. However, business ethics actually \\ add value for customers and result in increased profitability and performance for the firm.
}

\section{INTRODUCTION}

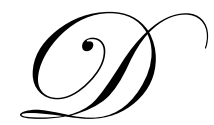

ue to constantly changing competitive environments, business organizations must find new methods to meet competition other than the traditional ways of better products (most consumers believe that competitive products are fairly equal in terms of quality), more services associated with a sell (more companies are finding that providing more and more services negatively affect profitability), or lower prices (competing on price results in erratic market share and unstable profits). Business organizations are responding to these challenges today by establishing partnerships and more collaborative relationships with their customers (Dertouzos, Lester and Solow 1989). Relative to these relationships there has been much discussion in the last several years regarding ethical practices by business organizations. For the most part, it has been assumed that organizations would do what was right for both their customers and their employees in the interest of long-term positive relationships. Unfortunately, we have learned the difficult lesson that such behavior is not always the norm. Unethical - and illegal - activities by such companies as Enron, WorldCom and Adelphi have shaken the foundation of trust that has formed the basis of marketplace relationships between companies and stakeholders. While there has been a greater focus on business ethics as a result of these companies' activities, questions are still asked regarding the financial return related to developing processes that insure absolute adherence to high ethical standards in organizations.

Ethics could be seen as a constraint on profitability. This view indicates that ethics and profit are inversely related (Bowie 1998). There are probably times when doing the right thing reduces profits. A more positive view, however, is that there is a positive correlation between an organization's ethical behaviors and activities and the organization's bottom line results. In fact, a reputation for ethical business activities can be a major source of competitive advantage. High standards of organizational ethics can contribute to profitability by reducing the cost of business transactions, building a foundation of trust with stakeholders, contributing to an internal environment of successful teamwork, and maintaining social capital that is part of an organization's market-place image.

The importance of business ethics to an organization has been discussed from differing viewpoints. Some managers consider ethics programs in their organizations to be very expensive activities that are only societally rewarding. Examples from the business community, however, suggest that companies viewed as ethical by the companies' stakeholders (i.e., customers, employees, suppliers, and public) do enjoy several competitive advantages. These advantages include higher levels of efficiency in operations, higher levels of commitment and loyalty from employees, higher levels of perceived product quality, higher levels of customer loyalty and retention, and better financial performance (Ferrell 2004). The link between ethics and profitability has been studied for several years. A study summarized 52 research projects examining the correlation between ethics and profits (Donaldson 2003). The results were encouraging for those supporting a positive linkage between the two variables. Of the 52 studies examined, 33 studies indicated a positive correlation between corporate ethics programs and profitability, 14 studies reported no effect or were inconclusive, and five indicated a negative relationship. Similarly, in a meta-analysis of 82 
studies, Allouche and Laroche (2005) found conclusive evidence that corporate social responsibility has a positive impact on corporate financial performance (with effects being strongest in the UK).

\section{VALUE PROFIT CHAIN}

In their book, The Service Profit Chain, Heskett et.al. (1997) indicate that companies such as American Express, Southwest Airlines, and Ritz-Carlton Hotels remain leaders in their respective industries by managing the service profit chain. The authors found strong correlations between three internal and market-place variables: (1) customer loyalty and profit; (2) employee loyalty and customer loyalty; and (3) employee satisfaction and customer satisfaction. The following diagram (Figure 1) illustrates these relationships.

Figure 1: The Service Profit Chain

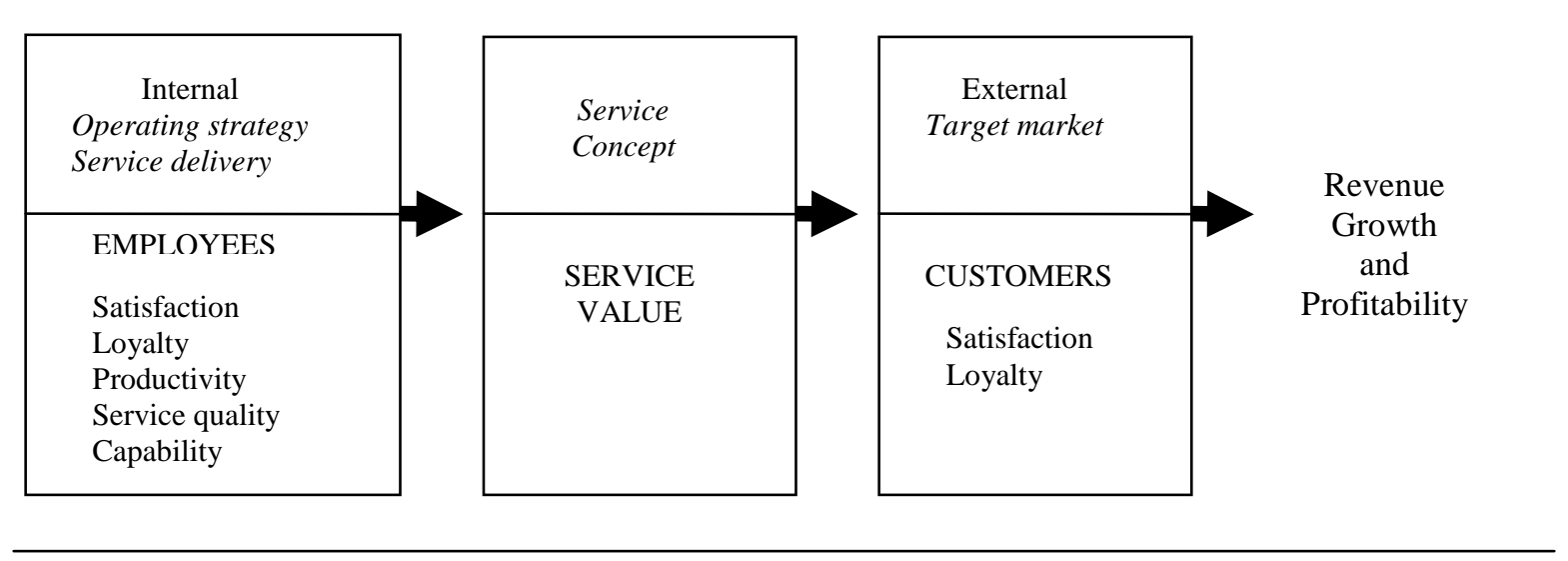

The service profit chain model was specifically developed to explain the relationships between employees and customers in a service environment. The model suggests that skilled employees who are highly satisfied with their jobs are much more loyal to the organization and far more productive in delivering high levels of quality service to customers. As a result of this high level of service, the organization's customers hold positive attitudes toward the company exhibited in high levels of customer satisfaction. This high level of satisfaction is exhibited in higher levels of loyalty. This high level of customer loyalty is expressed in customers' behaviors such as repeat purchases and referrals of additional customers. The end result of this chain is long-term and stable revenue growth and profitability.

While the service profit chain is applicable to organizations marketing services, we believe that the concept can be useful in managing for business growth and profitability in any types of organizations in which employees have direct contact with and interact with customers. Thus, we have extended the service profit chain model to include organizations marketing physical goods. The extended model is presented in Figure 2.

Figure 2: The Value Profit Chain

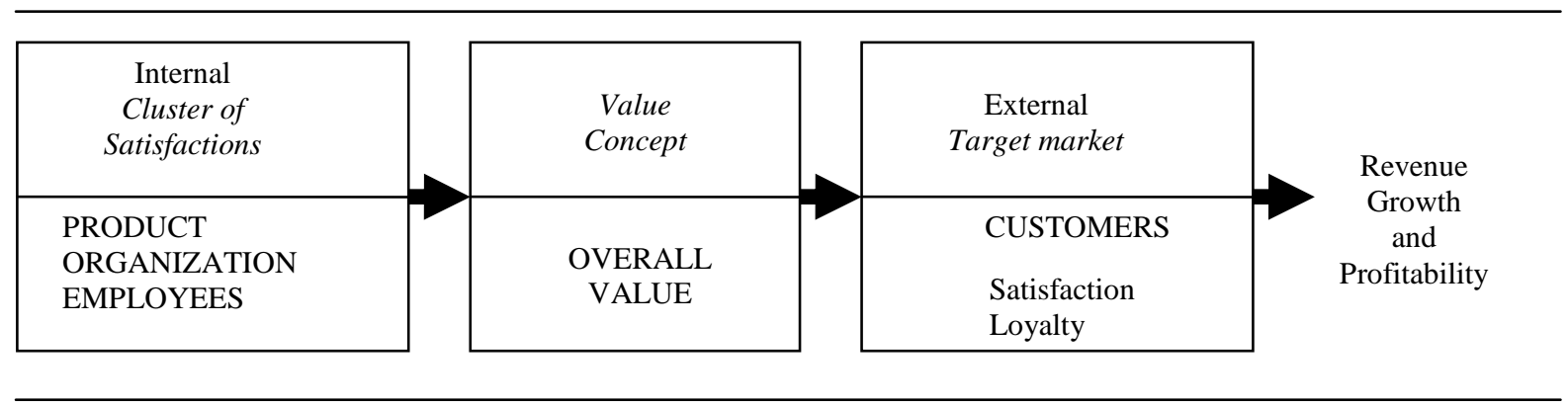


Central to our extended model is the concept of overall value that customers realize and perceive in business relationships with organizations. Unlike service products, in which a customer's perceived value is primarily correlated with contacts with service employees, perceived value in a physical goods environment is the result of several relationships (cluster of satisfactions). When customers purchase physical goods, they are acquiring a product from which they anticipate and expect some level of utility value. That is, the customer expects the product to provide desired personal advantages and benefits, either physically and/or psychologically. To acquire these need-satisfying products, customers usually have some direct contact with an organization and its employees (e.g., salespeople, customer service representatives, etc.).

\section{Cluster Of Satisfactions}

While customers purchase products for the results (utility value) they wish to realize, current marketing texts indicate that customers today are better educated and more demanding, and are seeking more than utility value from a product. These customers are redefining products as combinations of the physical good, the organization from which the product was acquired, and employees of the organization. These customers are seeking a cluster of satisfactions that arise from this combination of product, organization and employees (e.g., see Manning and Reese 2004). Customers expect this cluster of satisfactions to deliver high levels of perceived value from use of a product, interaction with an organization, and contact with an organization's representatives.

\section{Outcomes}

When customers perceive the relationship with an organization, through the cluster of satisfactions, to be of value, there are several positive outcomes for the organization. These customers are highly satisfied. While most companies survey their customers and measure levels of customer satisfaction, satisfaction is only an attitude. To ultimately be profitable for an organization, these attitudes of satisfaction must result in specific customer behaviors that increase revenue and profitability. These behaviors represent levels of customer loyalty to the organization. For example, highly satisfied customers should continue to purchase products from the organization in the future. These customers usually buy more often and purchase larger quantities when they do buy. Additionally, these customers refer other potential customers to the organization. Referred customers usually develop higher levels of satisfaction and loyalty at faster rates than did the referring customers.

\section{CUSTOMER VALUE}

Fundamental to the value profit chain model is the concept of customer value. Heskett et.al. (1997) developed a value equation to describe this concept of customer value. They described customer value in terms of two components - customer revenue and customer cost with the resulting customer profit (or loss) representing value to the customer in terms of (1) benefits in utilizing the product, (2) relationship with the company in purchasing the product, and (3) relationship with the company's representative (e.g., salesperson). Value, as perceived by the customer, is represented as:

$$
\begin{aligned}
& \text { Customer } \\
& \text { Value }
\end{aligned}=\frac{\text { Results Produced for the Customer }+ \text { Process Quality }}{\text { Price to the Customer }+ \text { Costs of Acquiring the Product }}
$$

The numerator in the customer value equation represents income or revenue (both real and psychological) to a customer. This customer revenue consists of results the customer realizes from actual use of a product or service and the overall quality of the process of initiating and maintaining a relationship with both the organization and the organization's representatives (e.g., salesperson). Value, as perceived by customers, is the difference between the personal revenue (results + process quality) generated and the personal cost (price + acquisition cost). The individual components of customer value are discussed below. The greater the positive difference between customer cost and customer revenue the greater the value of the product and relationships (organization and people) to the customer. 
Price

Customers often perceive the cost of purchasing a product in terms of economic price. The price of a product, however, can consist of more than just a financial price. In some cases, these additional components of a price can be of more importance than the actual economic outlay associated with purchasing a product. For example, there is a psychological component of risk inherent in a product's price. When we purchase products, we expect them to provide something of value or benefit to us. The more important the product is to a person; the more technically complex the product; and the more capital intensive the product, then the higher the level of risk that the product will not provide the expected advantages. Thus, the higher the price is perceived to be by individuals.

\section{Costs Of Acquiring The Product}

In addition to the economic price that customers pay to acquire products, there are additional investments associated with the purchase that increase the overall cost to the customer. A key component of these acquisition costs is the time and effort that customers must invest to physically acquire products. This investment of time and effort includes a customer's search for product information to make more informed buying decisions. Acquisition costs also include the time and effort that must be invested to travel to a store to actually see a product demonstrated.

\section{Results}

In the end, customers buy results (i.e., utility value), not features, when purchasing products and services. For example, when a customer wishes to drill a one-quarter inch hole in a panel and needs to purchase a quarter-inch drill bit from a hardware store, the customer is actually purchasing a quarter-inch hole, not a quarter-inch drill bit.

\section{Process Quality}

Heskett et.al. (1997) suggest that the way, or method, in which a service (or product in the value profit chain) is provided can be as important to customers as the results a service or product actually delivers. We define process quality as the business relationship between a customer and an organization and the personal relationship between a customer and representatives of the organization (e.g., salespeople, customer service representatives, etc.). Examples of components of process quality as it relates to a company include customers' perceived ease of negotiation in dealing with a business, ease of obtaining product information, ease of obtaining product service and responsiveness of service personnel.

Parasuraman, Zeithaml and Berry (1988) found that the quality of a service process consist of five dimensions. These dimensions of process quality are as follows:

- Dependability. A customer, for there to be value in a relationship with a business organization, must feel that the company and company representatives did what they promised they would do. The dimension of dependability is key to an organization's long-term growth and profitability as it is a major determinant of customer trust that leads to higher levels of customer retention.

- $\quad$ Responsiveness. For there to be value in relationships between customers and business organizations and company representatives, customers must feel that companies and representatives respond to customer needs in a timely manner.

- $\quad$ Authority. Customers must feel confident, for process quality to be perceived as high, that a company's customer contact personnel (e.g., salespeople, service personnel) have the authority to deliver on promises.

- Empathy. Customers must feel that both business organizations and an organization's representatives can see things from the customer's point of view. The business relationship between a customer and an organization must be based on a win-win philosophy on the part of the company.

- Results (tangible evidence). While the first four components of process quality are related to relationship items, customers still hold expectations regarding desired outcomes from the purchase and use of products. Thus, there is an element in process quality that is related to a customer's expected outcomes or utilitarian results. 


\section{ETHICS AND TRUST PROCESSES}

Partnering relationships with customers depend on exchange processes that are characterized by high levels of trust between the parties involved in an exchange (Morgan and Hunt 1994). There is some disagreement as to whether organizations can actually be targets of trust by customers (Doney and Cannon 1997). That is, customers actually develop trust in the representatives of an organization such as sales representatives and customer service personnel. The literature on trust, however, suggests that people (customers) do develop perceptions of trust in organizations (Morgan and Hunt 1994). It is somewhat intuitive that customers would develop perceptions of trust (or distrust) in organizations through contact with organizational agents since these contacts actually represent the organizations to the customers.

Our definition of trust is a combination of two elements related to an exchange partner. First, trust consists of the perceived credibility of an exchange partner (organization). Second, trusts consists of a person's perceived benevolence of an exchange partner (Kumar, Scheer and Steenkamp 1995). Credibility relates to an expectancy that the exchange partner's word, written statement (contract), or actions can be relied on. Benevolence relates to the degree that one exchange partner (the organization) is genuinely interested in the well-being of the other partner (the customer) and is seeking to develop a win-win relationship environment.

Doney and Cannon (1997) suggest there are five distinct processes by which customers develop trust in business relationships and organizations. These processes are as follows:

- $\quad$ Calculative process. In this process, an individual (customer) calculates the costs and/or rewards of the other exchange partner (organization) cheating the customer. If the costs of being caught outweigh the benefits of cheating, the customer will infer that it is in the best interest of the organization to be honest and can be trusted.

- $\quad$ Prediction process. The customer, in this process, examines past interactions with an organization and forecasts the organization's behaviors in future transactions. A customer comes to count on an organization relying on past experiences of ethical behaviors or actions.

- Capability process. This process focuses on the credibility element of trust. It involves determining the other exchange partner's (organization) ability to meet its obligations and deliver on its promises. A customer will infer a level of trust in an organization if the customer has reason to believe the organization can deliver products, services and support as promised.

- Intentionality process. In this trust process, a customer interprets the exchange partner's (organization) behaviors/actions and tries to determine the organization's intent in the exchange. That is, customers develop high levels of trust in business organizations when they believe the organization will tend to behave in ways that are in the customer's best interest. That is, a customer believes that an organization intends to do what is right.

- $\quad$ Transference process. Finally, a customer can develop trust in a business organization through the process of transference. In this process, a customer trusts an exchange partner (organization) because of the organization's relationship with a third-party trusted by the customer. For example, we tend to infer trust in business organizations if we have friends and/or relatives who deal with the company and have developed high levels of trust in the company based on these exchange experiences. A business organization's ethical behaviors and actions are the foundation of these trust processes.

\section{ETHICS AND CUSTOMER VALUE}

Of the four components of customer value (results, process quality, price, and customer access cost), ethics has a strong influence on customers' perceptions of the level of process quality in doing business with an organization. As defined above, customers' overall feelings regarding the quality of processes in maintaining a business relationship with an organization are based on customers' general perceptions of five key items (Parasuraman, Zeithaml and Berry 1988): (1) being able to count on an organization delivering on any promises made to a customer; (2) feeling that organizations and company representatives will respond to customer needs in a timely manner; (3) knowing that organizational representatives have the authority to deliver on commitments made to customers; (4) feeling that 
organizations see issues and opportunities from customers' points of view; and (5) being able to identify tangible results from using organizations' products and from maintaining business relationships with the organizations. Of these five process quality items, four are directly tied to organizational behaviors grounded in ethical business practices. First, an organization must be committed to delivering on promises made to customers. Second, organizations must quickly respond to customers' issues (e.g., complaints). Third, when company representatives make personal commitments to customers, the representatives are committing an organization to the promises that are either explicitly or implicitly made. Fourth, it is important ethically that organizations consider the impact of any actions or behaviors on customers. For example, Enron executives made bad internal management decisions resulting in unethical practices. These unethical activities, while primarily internal to the company, had far-ranging impacts in the marketplace on customers and all stakeholders in the company.

Business ethics, the foundation of the processes by which customers develop feelings of trust in organizations, very directly impacts customers' perceptions of the overall process quality in doing business with organizations. While customers might feel they are getting good results from using a company's products; that the price of the products is reasonable in the market compared to competitive products; and that the cost (time and effort) of attaining the products is in line, if customers do not trust organizations within the context of process quality, their perceptions of value in doing business with the company will be degraded. Overall, customers would rather pay higher prices and maintain business relationships with ethical and trusted organizations than get good price deals from organizations that do not deliver outstanding process quality.

\section{LONG-TERM PROFITABILITY}

The customer value profit chain model (see Figure 2) posits that high levels of perceived customer value result in high levels of customer satisfaction. This customer satisfaction leads to higher levels of customer loyalty. It should be pointed out that customer satisfaction and customer loyalty are two very different variables in the model. Customer satisfaction represents an attitude. That is, how does a customer feel about the business relationship with a business organization. Customer loyalty, on the other hand, is an action. That is, customers maintain business relationships and continue to do business with organizations. It is this customer loyalty that leads to three very profitable behaviors by customers. First, loyal customers purchase more from organizations over a given period of time generating higher levels of revenue compared to not-so-loyal customers. Second, loyal customers repeat purchases from organizations on a more frequent and longer period than do other customers. Third, loyal customers refer other prospects (e.g., friends, relatives, neighbors) to the organizations they trust and are highly satisfied with. These referred customers then become more satisfied and more loyal in a shorter period of time than did the referring customers.

These customers that are highly satisfied and highly loyal (based on perceptions of high customer value) to organizations are much more profitable than other less loyal customers. As indicated above, loyal customers generate more revenue. These loyal customers, however, cost much less to market to. Business organizations with high percentages of satisfied and loyal customers can invest less financial resources in costly marketing programs aimed at these customers. For example, high investments in promotions - as compared to attempting to increase market shares by attracting customers from competitors - are not required when marketing to a loyal customer base. Additionally, salespeople are not required to contact these loyal customers as often and the contacts that are made are to maintain positive and profitable relationships rather to directly sell products. Thus, these organizations that have delivered high levels of customer value through maintaining higher quality relational processes based on ethical behaviors have the potential to generate sustained growth and higher revenues over a longer period of time while incurring less marketing expenses resulting in stable and growing quarterly and long-term profitability.

\section{EXAMPLES}

Based on the concept of the value profit chain, the role of business ethics as it relates to process quality and resulting customer value perceptions is very apparent. We are, just now, in the initial stages of several research projects to empirically examine the validity of the value profit chain model. There are in the literature, however, anecdotal examples of the profitability of marketplace integrity. LeClair, Ferrell and Fraedrich, in their book Integrity 
Management (1998), describe five well-known successful companies that have invested organizational resources (both financial and people) in developing cultures of business ethics and integrity. Three of these companies are highlighted below.

\section{Hershey Foods}

Hershey is the leading confectioner in North America with sales exceeding $\$ 4$ billion. Ethical values are the foundation of the company's corporate culture. Hershey's business philosophy points to the company's ethical business culture.

- "Honesty, integrity, fairness and respect must be key elements in all dealings with our employees, shareholders, customers, consumers, suppliers and society in general."

- $\quad$ "Our operations will be conducted within regulatory guidelines and in a manner that does not adversely affect our environment."

- $\quad$ "Employees will be treated with respect, dignity and fairness."

- $\quad$ "Our ongoing objective is to provide quality products and services of real value at competitive prices that will also insure an adequate return on investment."

It is interesting to note that, in Hershey's business philosophy, the concepts of honesty, integrity, fairness and respect are listed first and before the concept of adequate return on investment.

\section{Waste Management, Inc.}

Waste Management has a small trash collection service. Today, the company is the largest solid waste and disposal company in the world with annual sales of over $\$ 9$ billion. Several years ago the company was fined $\$ 2$ million for antitrust violations and another $\$ 12$ million for violation of pollution ordinances. Waste Management is working hard to establish a culture of ethical business behaviors. The company developed a code of ethics and established training programs to insure employees understood exactly what the company expected of them when faced with ethical issues. Employees are continually reminded that the characteristics of fairness, honesty, integrity and trust lead to a marketplace reputation of delivering high levels of value to customers. This reputation has resulted in a high level of satisfaction and loyalty among the company's customers.

\section{Home Depot}

Home Depot is the world largest retailer of do-it-yourself products for the home. The company has over 500 stores in North America and annual sales of over \$20 million. The company has been commended for its ethics training workshops for employees. A key component of the company's business philosophy is that when "employees believe in the ethical correctness of their workplace arrangements, their employer gains their support and loyalty." This employee loyalty has translated into high levels of customer value based on customer satisfaction and loyalty. This employee loyalty is important in the delivery of customer value. When you look at the components of process quality in the customer value equation, all five (dependability, responsiveness, authority, empathy, and tangible results) are dependent on the interactions of employees with customers. Home Depot is proof that when employees value the relationship with an organization (based on fairness and integrity in employee-organization relationships), the employee loyalty that results is passed on to customers because of more positive relationships between employees and customer.

Unfortunately, we have several examples today of companies that have suffered financially for ethical lapses. ENRON, Global Crossings, and World Com are either gone from the business landscape or exist in very different forms. These examples of ethical missteps didn't cost just the companies' customers. The negative financial impact on employees who had invested their retirement in the companies was astronomical. Additionally, investors lost millions of dollars due to the negative impact these companies had on the financial markets. 


\section{CONCLUSION}

Certainly, there are companies that still believe that unethical business practices will not be discovered and there will be no negative business implications. In fact, we will most likely see more ethical lapses among business organizations in the future. There are still two good reasons that business organizations should be concerned about their ethical reputations (Business Ethics 2003). First, unethical business practices, once they have become public, can lead to government intervention and regulations that are more problematic to businesses than self-policing in the first place. Such regulations can prove to be not only limiting in terms of what a business can and cannot do (both externally in the market and internally related to labor and accounting practices), but also financially costly for companies to adhere to. Second, and even more important than governmental intervention, is trust. Companies lacking trust by employees, business partners, and customers will suffer financially in the long-term. Trust, based on ethical reputations, may become even more important in the future. We live in an ever increasing e-commerce world where business organizations are becoming geographically far-removed from their customers. In such an environment, customer trust based on reputations grounded in the process quality component of customer value is even more important to the long-term growth and profitability of companies.

\section{REFERENCES}

1. Allouche, Jose and Patrice Laroche (2005), A Meta-Analytical Investigation of the Relationship Between Corporate Social and Financial Performance, Revue de Gestion des Ressources Humaines. Paris: Jul-Sep 2005., Iss. 57; pp. 18-42.

2. Bowie, Norman E., (2000), Companies Are Discovering the Value of Ethics, Business Ethics 00/01, $12^{\text {th }}$ ed., John E. Richardson Editor, McGraw-Hill/Dushkin, Guilford, Connecticut, pages 150-152.

3. Business Ethics (2002/2003), 14 ${ }^{\text {th }}$ ed., John E. Richardson Editor, McGraw-Hill/Dushkin, Guilford, Connecticut.

4. Dertouzos, Michael L., Richard K. Lester, and Robert M. Solow (1989), Made in America:Regaining the Productive Edge, Cambridge, MA, The MIT Press.

5. Donaldson, Thomas (2003), Adding Corporate Ethics to the Bottom Line, Business Ethics 03/04, $15^{\text {th }}$ ed., John E. Richardson Editor, McGraw-Hill/Dushkin, Guilford, Connecticut, pages 98-101.

6. Doney, Patrica M. and Joseph P. Cannon (1997), An Examination of the Nature of Trust In Buyer-Seller Relationships, Journal of Marketing, 61 (April), pages 35-51.

7. Ferrell, O.C. (2004), Business Ethics and Customer Satisfaction, Academy of Management Executive, 18, number 2 (May), pages 126-129.

8. Heskett, James L., W. Earl Sasser, Jr., and Leonard A. Schlesinger (1997), The Service Profit Chain, The Free Press, New York, New York.

9. Kumar, Nirmalya, Lisa K. Scheer, and Jan-Benedict E.M. Steenkamp (1995), The Effect of Perceived Interdependence on Dealer Attitudes, Journal of Marketing Research, 32 (August), pages 348-356.

10. LeClair, Debbie Thorne, O.C. Ferrell, and John P. Fraedrich (1998), Integrity Management, University of Tampa Press, Tampa, Florida.

11. Manning, Gerald L. and Barry L. Reece (2004), Selling Today, $9^{\text {th }}$ ed., Prentice Hall, New Jersey, page 126.

12. Morgan, Robert M. and Shelby D. Hunt (1994), The Commitment-Trust Theory of Relationship Marketing, Journal of Marketing, 58 (July), pages 20-38.

13. Parasuraman, A., Valerie A. Zeithaml, and Leonard Berry (1988), SERVQUAL: A Multiple-Item Scale for Measuring Consumer Perceptions of Service Quality, Journal of Retailing, Spring, pages 12-40. 